\title{
Implementation of Autonomous Sensor-Based E-Waste Monitoring System
}

\author{
K. Naveena and Santhosh B Panjagal \\ Kuppam Engineering College, Kuppam, Andhra Pradesh, India \\ Corresponding author email: bhavinaveena@gmail.com
}

\section{ABSTRACT}

Air quality of the environment we are living in is reducing day by day due to increased human activities like; biomass burning, automobiles, landfilling, illegal burning of Electronic waste (E-waste), urbanisation and industrialisation. Illegal burring of electronic waste (E-waste) releases many air pollutants along with toxic heavy metals $(\mathrm{Pb}, \mathrm{Hg}, \mathrm{Ni}, \mathrm{Cr}$ and $\mathrm{Cd}$ ) into the surrounding environment which poses high risk to the environment and human health. Therefore to address the problem of air pollution and their associated health effects, we proposed to develop an intelligent system which measures the air pollutants concentration by categorising air pollutants particles size falling under $2.5 \mathrm{u} / \mathrm{m} 3$ and $2.5 \mathrm{u} / \mathrm{m} 3$ to $10 \mathrm{u} / \mathrm{m} 3$ by using PM2.5 and PM10 particulate matter laser sensors. After measuring the air pollutants concentration at any selected site, the measured data was uploaded to the Internet of Things (IoT) Cloud for storage and remote monitoring for further risk assessment. User-friendly mobile application was developed to access the air quality information from the IoT cloud of the selected E-waste burning site and health risk assessment is done according to the standard regulatory guidelines set by Environmental protection agency(EPA) and ACGIH. Based on the measured air pollutants concentration, the application predicts the Air quality index (AQI) category and alerts the users about associated health symptoms and precautionary measures.

KEY WORDS: PARTICULATE MATTER, PM2.5, PM10, AIR QUALITY, AQI, IOT AND USER-FRIENDLY MOBILE APPLICATION.

\section{INTRODUCTION}

According to the World Health Organization (WHO), around 7 million people dies of due to air pollution worldwide every year and due to outdoor air pollution approximately 3.4 million people died prematurely in 2017 (WHO). WHO data shows that 9 out of 10 people breathe air that exceeds WHO guideline limits containing higher concentrations of air pollutants and most of the deaths occurred in the developing countries (World Health Organization, 2014) like India, china etc. suffering from the highest exposure to ambient air pollution. Following tobacco smoking and household air pollution from solid fuels, ambient air particle pollution became the third

Biosc Biotech Res Comm P-ISSN: 0974-6455 E-ISSN: 2321-4007

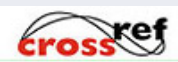

Identifiers and Pagination

Year: 2021 Vol: 14 No (9) Special Issue

Pages: 184-188

This is an open access article under Creative

Commons License Attribn 4.0 Intl (CC-BY). DOI: $h t t p: / / d x$.doi.org/10.21786/bbrc/14.9.35 leading environmental health risk to premature death in the developing countries (about 45 deaths per 100,000 people) (Sengupta \&t 2019 \&t Chen et al., 2015).

India is been considered as one of the fast growing economy in the world since last decade, but this extensive growth has come at a substantial cost to the environment and public health in India. Nowadays, India has become one of the largest producer of major air pollutants in the world, and serious air pollution has risen a concern of people and the authorities with the consideration of public health damage and economic loss. As we know, various kinds of air pollutants release from different kinds of sources, such as industry, vehicle, waste combustion, power plant, cooking and so on. In addition, many of the released pollutants would make a series of reactions with each other in the mix air family under different conditions (Hong et al., 2018).

Therefore, they defer in chemical property, physical characteristics, transportation ability, as well as human toxicity and so on. However, based on their some

\section{Article Information}

Received: 04 ${ }^{\text {th }}$ June 2021 ccepted after revision: $19^{\text {th }}$ July 2021 
similarities and the major air pollution styles, they are grouped into four categories (Kampa and Castanas, 2008): (1) particulate matter (PM); (2) gaseous (air) pollutants; (3) heavy metals; (4) persistent organic pollutants (POPs) (Hemalatha et al., 2019).

Gaseous or air pollutants refer to Ammonia(NH3), sulphur dioxide (SO2), nitrogen oxide (NOx), Hydrogen Sulphide(H2S), carbon monoxide (CO), ozone (03), volatile organic compounds (VOCs) in most of the time. Due to their great contribution to the polluted air and prevalently found in different kinds of emission sources, this group of pollutants was firstly in regulations in the world. They were listed as Criteria Air Pollutants in the first US EPA Clean Air Act in 1997 except for VOCs, which had been listed in regulation since 2003. They are mostly the products of combustion of fossil fuels, various industrial processes, and motor vehicles (Katsouyanni, 2003; Sager 2019).

Particulate matter (PM) is the generic term used for the suspended particles varying in size and composition and could be produced by various natural and anthropogenic activities. In the US EPA Clean Air Act, particles less than 10 micrometres in diameter (PM10) and 2.5 micrometres in diameter (PM2.5) are in the list of Criteria Air Pollutants. It was proposed that PM10 can get deep into human lungs and thus will cause greater problems than the coarse one. Fine particles (PM2.5) are proved the major cause of visibility reduction thus cause haze days (Tsai, 2005). Moreover, due to the smaller size of fine particles, they can go deeper into human lungs and cause short-term irritation, affect lung function and result in asthma and heart diseases (Panjagal et al., 2021).

Fine particle pollution is now identified as a major risk globally. The air quality has to be maintained for protecting human health, the World Health Organization (WHO) provides the threshold pollutant concentration levels to limit harmful effects on human mortality. The daily and annual limits of fine PM (PM2.5, which has a diameter less than or equal to $2.5 \mu \mathrm{m}$ ) do not exceed 25 and $50 \mu \mathrm{g} / \mathrm{m} 3$, respectively. However, there is no specific recommendation for safe PM limits concerning cognition and mental health (Sebastien et al., 2011).

Air pollution causes premature death of human being and it is a significant risk factor for the number of pollutionrelated diseases including heart disease, respiratory infections, stroke and lung cancer. The health problem caused by air pollution includes coughing, difficulty in breathing, wheezing, asthma, and worsening of existing respiratory and cardiac conditions. These may result in increased medication use, more hospital admissions and premature death (Shehab \& Pope 2019).

Air quality monitoring is essential for major public and private industrial sectors to prevent air pollution and measure emission sources to impose more stringent measures in order to mitigate outdoor air pollution especially from illegal e-Waste burning in waste dumping yards. So to address the issues associated with indoor and outdoor air pollution, in this research work we proposed to design an autonomous sensing system for E-waste monitoring to measure the air quality at the waste dumbing sites and other general places. The system measures the air quality at selected site in real-time and then stores the data on IoT cloud for remote monitoring and further assessment in mobile application.

\section{MATERIAL AND METHODS}

2.1. Study Area: The municipal and electronic waste dumping site at Chittoor Town, Andhra Pradesh, India has been selected for studying the outdoor ambient air pollution, air quality in surrounding sites and Risk assessment based on standard guidelines formulated by Environmental Protect Agency (EPA), American Conference of Governmental Industrial Hygienists (ACGIH) etc.,. Apart from measuring the air quality at E-Waste, we proposed to measure the air quality at most common places like Organizations, carpentry/wood working sites, public places etc.

2.2. Methodology: Our proposed research work involves following methodologies;

- Design of Air Quality (e-Waste) monitoring System

- Mathematical modelling of Sensors

- Data Processing, Storage \&t Assessment

2.2 Design of Air Quality (e-Waste) monitoring System: In this research work, we designed an autonomous sensing system for E-waste monitoring to measure the air quality at the waste dumbing sites and other general places. This air quality monitoring system incorporates industrial sensors like; SDS011 (PM2.5 and PM10) optical dust particle sensor, and TGS2602 senor for measuring air pollutants ammonia (NH3), Iso-butane or benzene, H2S, and Volatile organic Compounds(VOC's) including smoke. The local processor (NodeMCU) measures the concentration of air pollutants, particulate matter (PM) particle size up to $2.5 \mathrm{ug} / / \mathrm{m} 3$ and particle sizes ranging above $2.5 \mathrm{ug} / \mathrm{m} 3 \mathrm{up}$ to $102.5 \mathrm{ug} / \mathrm{m} 3$ concentration and displays on OLED display for real-time monitoring. Then whole data was uploaded on to Internet of Things (IoT) cloud for storage and further assessment through remote access via mobile applications. The figure 2.1 shows the E-Waste monitoring system block diagram.

2.2 Mathematical modelling of Sensors: As we used industrial gas sensors for real-time measurement of airpollutants and Particulate matter concentrations, these sensors needs to be calibrated, and then output voltage of the sensor has been converted into parts per million (ppm) units by developing the mathematical model using power regression analysis. The sensitivity curve of TGS2602 sensor was used to find the coefficients A and B using either straight-line method or power regression analysis. Figure 1.2 shows the basic measurement circuit of TGS2602 gas sensor (Swati et al., 2019). 
Figure 2.1: E-waste Monitoring device

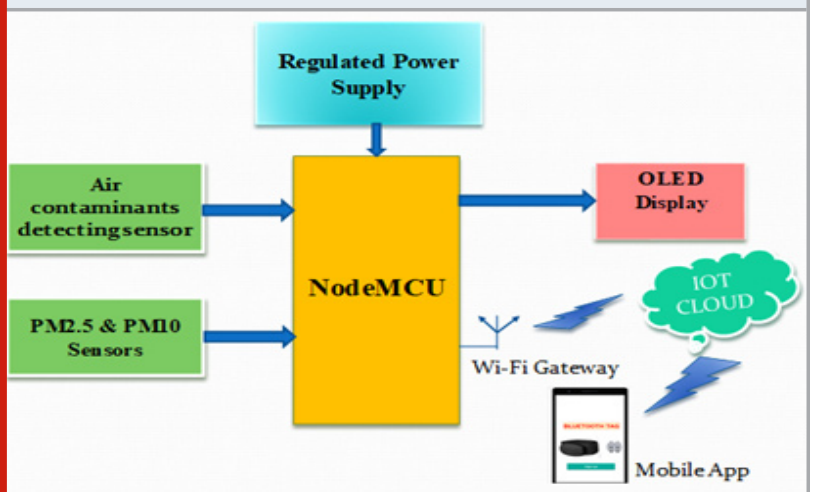

The sensor resistance Rs can be determined using Ohm's Law: $\mathrm{V}=\mathrm{I} \times \mathrm{R}$----(1)

from basic measuring circuit is output current is equal to: $\mathrm{I}=\mathrm{VC} /(\mathrm{Rs}+\mathrm{RL})$---(2)

Ro: sensor resistance in the clean air.

Rs: sensor resistance at various concentrations of gases.

Then; Rs $=[(\mathrm{Vc} \times \mathrm{RL}) / \mathrm{VRL}]-\mathrm{RL}$

The output resistance Ro was calculated by calibrating the sensor in clean air and under standard test conditions. After measuring Sensor resistance Rs, the ratio of Rs/ Ro calculated to determine the gas concentration in ppm using coefficients obtained from power regression analysis. The following equation (4) is used to calculate the gas concentrations in ppm (Xu \&t Yang 2019).

$\mathrm{X}$ ppm $=$ Coefficient $(\mathrm{A})^{*}(\mathrm{Rs} / \mathrm{Ro})^{\wedge}{ }^{\text {coefficient }}(\mathrm{B})$

The conversion of air pollutants PM2.5 and PM10 particles size in parts per million to micrograms per cubic meters is given below equation (5),

Concentration $\left(\mathrm{ug} / \mathrm{m}^{3}\right)=$ concentration $(\mathrm{ppm})^{*}\{$ molecular mass(g/mol)/molar volume(L)\}------(5)

The AQI provides an indication of the quality of the air and its health effects. The index value for pollutant can be calculated as given in equation (6);

$$
I_{P}=\frac{I_{H i}-I_{L O}}{B P_{H i}-B P_{L_{0}}}\left(C_{P}-B P_{L_{0}}\right)+I_{L_{0}}
$$

Where;

Cp is the truncated concentration of pollutant (p)

$\mathrm{BP}_{\mathrm{Hi}}$ is the breakpoint that is greater than or equal to $\mathrm{Cp}$

$\mathrm{BP}_{\mathrm{Lo}}$ is the breakpoint that is less than or equal to $\mathrm{Cp}$ $\mathrm{I}_{\mathrm{Hi}}$ is the $\mathrm{AQI}$ value corresponding to $\mathrm{BP}_{\mathrm{Hi}}$
$\mathrm{I}_{\mathrm{Lo}}$ is the $\mathrm{AQI}$ value corresponding to $\mathrm{BP}_{\mathrm{Lo}}$

2.3 Data Processing, Storage \&t Assessment: As the entire system involves air pollutants measurement and monitoring, hence the measured data needs to be processed at various stages of the research development. The local processor reads concentration of air pollutants in ppm and their particulate matter concentration in $\mathrm{ug} / \mathrm{m} 3$ using sensors, hence the data processing done by applying mathematical modelling algorithms to convert the output voltage levels into air pollutant gas concentration in parts per million (ppm) and particulate matter (PM) concentration in $\mathrm{ug} / \mathrm{m} 3$. After data processing, measured concentration data was uploaded to IoT cloud for storage and further studies.

\section{Figure 3.1: e-Waste monitoring Device}

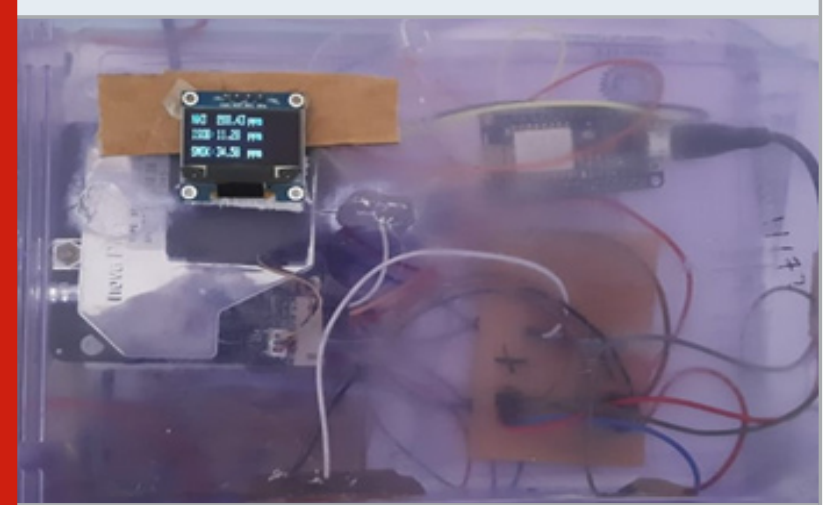

Figure 3.2: Air pollutants concentration in normal air and $\mathrm{PM}$ concentration in indoors

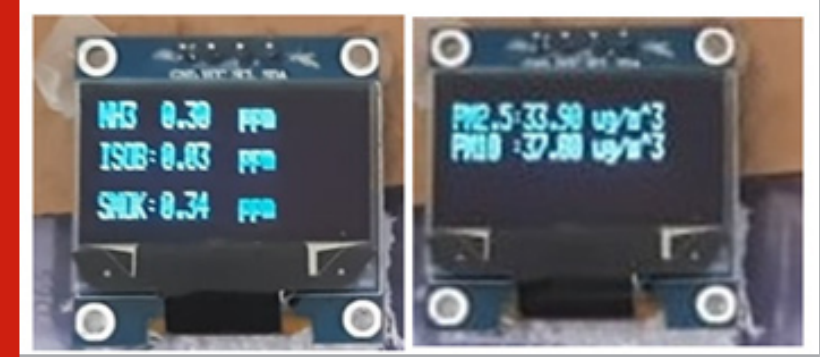

Figure 3.3: Pollutants Concentration when device was exposed to air pollutants

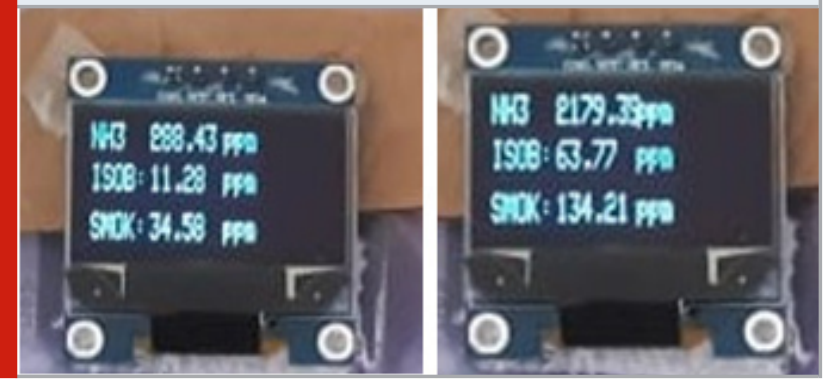

The data stored onto the IoT cloud helps us to further assess the data using user-friendly user interfaces like mobile/web applications or remote monitoring and 
decision making purposes. A health impact of particle pollution has been performed using risk assessment at the end user mobile application. In this assessment, the measured air pollutant and particulate matter concentration was compared against the standard safety guidelines provided by the Environmental Protect Agency (EPA), American Conference of Governmental Industrial Hygienists (ACGIH), NIOSH, OSHA etc.,. If the measured concentration exceeds threshold limit or safety value, the application will alert the user about the possible health effects/symptoms based on air quality category for 8-hour or 24-hour long exposure.

\section{RESULTS AND DISCUSSION}

In this proposed work, we developed an autonomous sensing device for e-Waste monitoring and assessment of air quality at the surrounding of selected study site as shown in figure 3.1

The device was tested against various environments like, clean air, indoors, laboratories, manual exposure for pollutants and selected sites. The Figure 1.7 shows the air pollutants concentration when the device was exposed to air pollutants.

Apart from displaying the measured real-time data on OLED, the data was uploaded to ThingSpeak IoT cloud for storage and real-time monitoring through remote access. Different fields are used to store and show the sensor data graphically. The field 1 and Field 2 are used to draw PM2.5 and PM10 data as shown in figure 3.4.
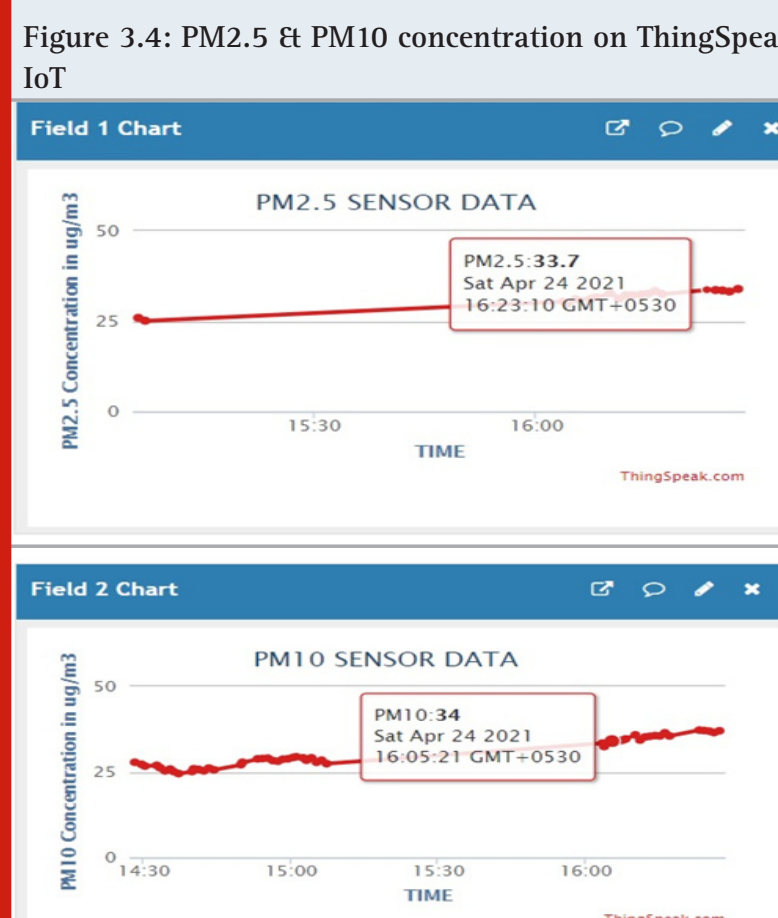

The field3 to Field5 are used to draw Ammonia (NH3), Iso-Butane and Smoke data as shown in figure 3.5
To perform the risk assessment and allow the users to know real-time information about the air quality at measured sites, the data stored on IoT was accessed on user-friendly mobile applications using read API keys as shown in figure 1.10 (Zeba et al., 2018).

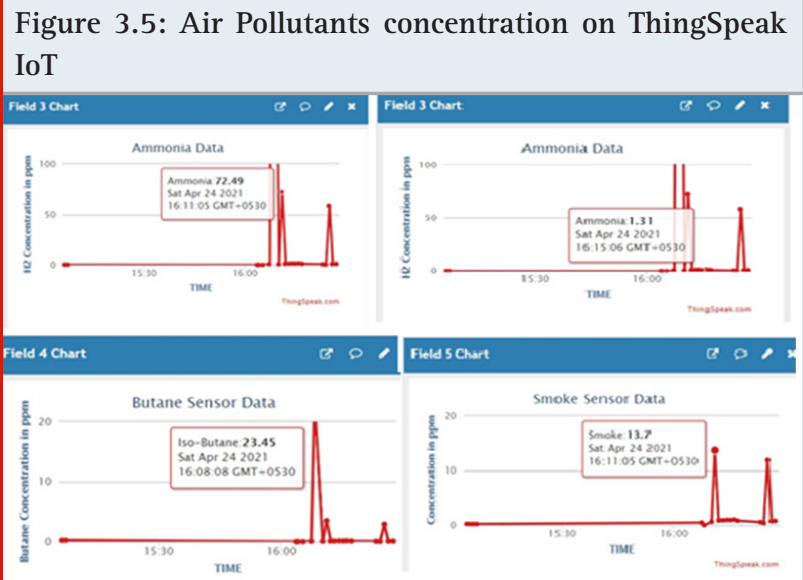

Figure 3.6: Real-time data of air pollutants, air quality and their health symptoms alert IoT Mobile Application

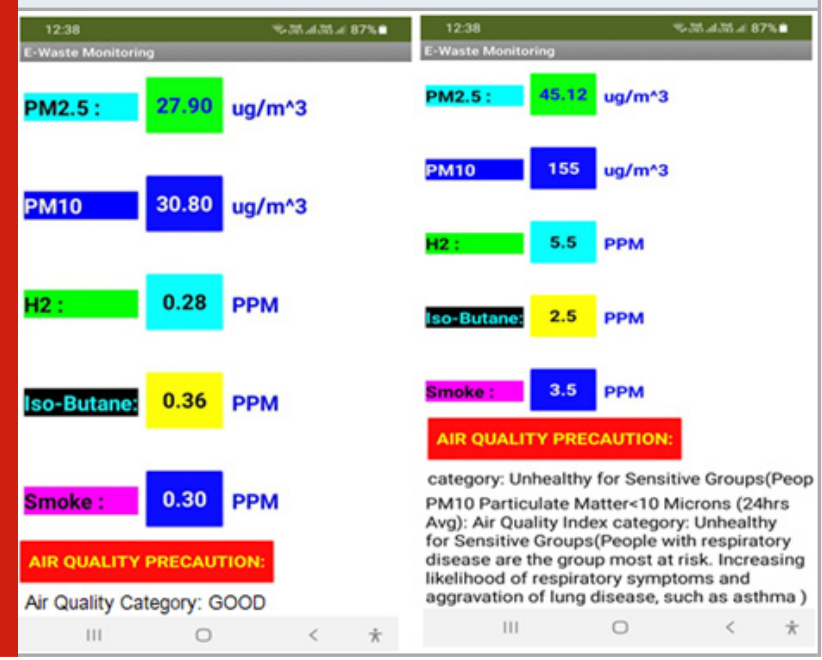

After reading the data from IoT, the mobile application perform risk assessment, the measured air pollutant and particulate matter concentration was compared against the standard safety guidelines provided by the Environmental Protect Agency (EPA), American Conference of Governmental Industrial Hygienists (ACGIH), NIOSH, OSHA etc.,. If the measured concentration exceeds threshold limit or safety value, the application will alert the user about the possible health effects/ symptoms based on air quality category for 8-hour or 24-hour long exposure.

\section{CONCLUSION}

The development of Autonomous sensing device for monitoring air quality at e-waste dumping site, shown satisfactory performance in terms of sensing air pollutants and particulate matter with good accuracy and 
measurement. The air quality measurement was done at various outdoor and indoor places apart from e-Waste dumping sites and uploaded to IoT cloud for storage, further assessment and remote access at end user mobile application for monitoring and alerting. The IoT mobile application provides real-time data of measurement and performs risk assessment by comparing real-time air pollutants concentration against the standard guidelines on threshold limit values and safety values formulated by EPA, ACGIC, NIOSH and OSHA. After comparing if any air pollutant concentration exceeds threshold limit or safety value, the application will alert the user about the possible health effects/symptoms based on air quality category for 8-hour or 24-hour long exposure. Hence the real-time implementation of this system at various outdoor public places will be very useful for alerting air quality index and their symptoms to the public, which in turn reminds the public to take necessary measures to mitigate inhaling of unhealthy air.

\section{REFERENCES}

A. Sengupta, V. Varma, M. Sai Kiran, A. Johari, Marimuthu R, (2019). Cost-Effective Autonomous Garbage Collecting Robot System Using IoT And Sensor Fusion, International Journal of Innovative Technology and Exploring Engineering, 9 pp. 1-8.

Chen Xiaojun, Liu Xian-peng, Xu Peng, (2015). IoT-based air pollution monitoring and forecasting system, International Conference on Computer and Computational Sciences (ICCCS) pp. 257-260. D0I:10.1109/ICCACS.2015.7361361

Hong Chen, Qiongsi Li MMath, Jay S Kaufman, Jun Wang, Ray Copes, Yushan Su, Tarik Benmarhnia, (2018). Effect of air quality alerts on human health: a regression discontinuity analysis in Toronto, Canada, The Lancet Planetary Health 2 e19-e26. DOI:10.1016/ S2542-5196(17)30185-7

K.Hemalatha, T.Srinivas, G.Swetha, V.Haripan, (2019). Effect of Air Quality Parameters in Hyderabad and Mapping Using QGIS and Detection Management
Software, International Journal of Innovative Technology and Exploring Engineering, 9 pp. 73-80.

Lutz Sager, (2019). Estimating the effect of air pollution on road safety using atmospheric temperature inversions, Journal of Environmental Economics and Management 98 , 102250. DOI:10.1016/j.jeem.2019.102250.

Lutz Sager, (2019). Estimating the effect of air pollution on road safety using atmospheric temperature inversions, Journal of Environmental Economics and Management 98 102250. DOI:10.1016/j.jeem.2019.102250.

Panjagal, S. B., Ramaiah, G. N. K. (2021). OdorSense: Measuring, Assessment and Alerting the Health Effects of Odor Pollution. 3C Tecnología. Glosas de innovación aplicadas a la pyme, Edición Especial, 91-107. https:// doi.org/10.17993/3ctecno.2021.specialissue7.91-107

Sebastien Humbert, Julian D. Marshall, Shanna Shaked, Joseph V. Spadaro, Yurika Nishioka, Philipp Preiss, Thomas E. McKone, Arpad Horvath, and Olivier Jolliet, (2011). Intake Fraction for Particulate Matter: Recommendations for Life Cycle Impact Assessment, Environmental Science \& Technology 45 4808-4816. DOI: 10.1021/es103563z.

Shehab M.A, Pope F.D, (2019). Effects of short-term exposure to particulate matter air pollution on cognitive performance, Sci Rep 9 8237. DOI:10.1038/s41598-01944561-0

Swati Dhingra, Rajasekhara Babu Madda, Amir H. Gandomi, Rizwan Patan, Mahmoud Dane, (2019). Internet of Things Mobile-Air Pollution Monitoring System (IoT-Mobair), IEEE Internet of Things Journal, 6 pp.5577-5584.

$\mathrm{Xu}$ Luo, Jun Yang, (2019). A Survey on Pollution Monitoring Using Sensor Networks in Environment Protection, Journal of Sensors, Article ID 6271206.

Zeba Idrees, Zhuo Zou, Lirong Zheng, (2018). Edge Computing Based IoT Architecture for Low Cost Air Pollution Monitoring Systems: A Comprehensive System Analysis, Desi 